\title{
Knowledge and Health Care Seeking Behaviors of Old Age Patients with Benign Prostatic Hyperplasia at Assiut University Urology Hospital, Egypt
}

\author{
Sanaa Abdallah Moukhtar ${ }^{1}$, Diaa Eldin Abdel Hameed Mohamed ${ }^{2}$ \& Hanan Abd Allah Abozeid ${ }^{3}$. \\ ${ }^{1}$ Nursing Supervisor in Health Administration of Assiut District affiliated to Health Directorate \\ 2. Professor of Urology Surgery, Faculty of Medicine, Assiut University, Egypt \\ 3. Assistant Professor of Gerontological Nursing, Faculty of Nursing, Assiut University, Egypt
}

\begin{abstract}
:
Background: Benign prostatic hyperplasia is a prevalent disorder in geriatric people. It has an impact on the physical health of those over the age of 65 and interferes with their everyday activities. Study aim: To assess the knowledge and health care seeking behaviors among old age patients with Benign Prostatic hyperplasia at Assiut University Urology Hospital. Research design: a descriptive cross-sectional research design was used. Sample: old age patients aged 60 years and above diagnosed with benign prostatic hyperplasia. The total sample size was 218 elderly. Setting: The study was carried out in an outpatient clinic at the Urology Hospital of Assiut University. Tools: Three tools were used; the first tool was an interview-structured questionnaire that includes demographic data, and patients' knowledge regarding benign prostatic hyperplasia. The second tool was the questionnaire of health care seeking behaviors and the third tool was the International Prostate Symptom Score. Results: Ninety percent of the sample have a poor level of knowledge and 39.9\% of them have sever benign prostatic hyperplasia symptoms, majority of them $83 \%$ are seeking health care when suffering from bothersome urinary symptoms. Conclusion: The majority of the patients in this study have a poor knowledge score regarding benign prostatic hyperplasia and seeking medical advice when they suffering from bothersome urinary symptom and fear of urinary retention. Recommendation: Providing booklet or handout to improve the knowledge of elderly patients about benign prostatic hyperplasia disease: causes, risk factors, treatment, and complications.
\end{abstract}

\section{Keywords: knowledge, Elderly, Health Seeking Behaviors \&Benign Prostatic Hyperplasia.}

\section{Introduction:}

Aging is caused by the accumulation of several types of molecular and cellular damage over time. This results in a gradual loss of physical and mental capacity, increased disease risk, and, eventually, death. However, these changes are not linear nor consistent, and they are only tangentially related to a person's chronological age (WHO, 2019).

The global population aged 60 years or above numbered 962 million in 2017, by 2050, the number of elderly people is estimated to more than double, reaching over 2.1 billion. Between 2017 and 2050, the number of people aged 80 and more is expected to more than triple, rising from 137 million to 425 million globally. (Mason, 2017).

Egypt's population climbed from 94.8 million in 2017 to 98.1 million in the first quarter of 2019. The average life expectancy at birth rose from 71.9 years in 2017 to 72.7 years in 2019, with those aged 65 and up accounting for 5.95 percent of the population. (Central agency for mobilization \& statistics, 2019).

Benign Prostatic Hyperplasia (BPH) is a common health disease that affects older men and can cause unpleasant Lower Urinary Tract Symptoms (LUTS).
Symptoms of BPH appear after the age of 40 , and by the age of 60 , the incidence has increased to more than $50 \%$, and by the age of 85 , it has increased to $90 \%$. Obstructive urine incontinence as one of LUTS, are common in BPH patients. (Ali et al., 2018).

Health seeking behavior of older adults influences their personal health practices which at the end affect the ability to seek medical intervention when sick or in illness (Michalak et al., 2015) Health seeking behavior can be improved through creating men's clinics and integrating some health services (Ngugi et al., 2017) Lack of awareness about the condition results in late diagnosis and therefore negatively affecting its prognosis. If the condition is diagnosed early the patient can be able to start utilizing the management services early enough before the condition worsens, this s positively influences the prognosis (Deep et al., 2017).

Socio-cultural aspects may impact patient's use of health care services, such as screening, counselling and clinical services. The individual's level of education is a key factor in seeking health services since it increases the level of awareness on BPH Saigal et al., (2015). 
Educations empowers people with knowledge and life skills on specific health issues as well as appropriate preventive mechanisms thus increasing the possibility of seeking for such services Ebere, (2016).

Nodular overgrowth of BPH occur in epithelial and fibromuscular tissue in the transition zone and peri urethral areas, is initially detected in the fourth decade of life and affects virtually all men by the ninth. The etiology of BPH is still completely unknown, however, several partially overlapping and complementary explanations have been developed, all of which appear to be operational. (Kuang et al., 2017)

The symptoms of LUTS involving the bladder and urethra. It can be caused by a variety of conditions, but its most commonly linked to BPH. symptoms of LUTS subdivedid into the symptoms (urinary voiding ,straining to void, urinary intermittency, dysuria, micturition dribbling, increased risk of urinary tract infections and urinary retention, hesitancy,.) symptoms of urinary storage (urgency, frequency, nocturia, need to urinate frequently, waking at night to urinate) and post-voiding symptoms (a sensation of incomplete emptying, uncontrollable leaking after end of urination. (Lee et al., 2017)

Gerontological nurse have an important role in promoting good patient compliance through patient education about BPH disease, proper administration of medication, and connecting patients with other supportive services. Frequent contact with patients put the nurse in an ideal position to prevent or minimize complications and to play an instrumental role in managing patients with urological diseases, organizing and delivering education sessions that help in urinary retention, and apply standardized care for aged people (Lewis, et. al., 2014)

\section{Significance of study:}

The most common problem among older men was $\mathrm{BPH}$ and is responsible for considerable voiding dysfunction About 25-50\% of men those sufferings from BPH have LUTS by the age of 85 years old, $90 \%$ of men will be bothered by their symptoms of BPH (Almakhan et al., 2018)

Men generally see LUTS as an inevitable result of aging, according to studies, and they are undereducated about their symptoms. They frequently postpone consultations, owing to uncertainty or cognitive impairment, but also by reason of more deliberate neglect. (Fan et al., 2017).

\section{Aims of the study:}

To assess the knowledge and health care seeking behaviors among old age patients with Benign Prostatic hyperplasia at Assiut University Urology Hospital.
Research questions:

- What is the level of knowledge of old age patients regarding $\mathrm{BPH}$ ?

- What are the behaviors of old age patients' with $\mathrm{BPH}$ for seeking health care?

\section{Subjects and Method:}

Research design: a descriptive cross-sectional research design was used.

Setting: The present study was performed in the general urological out-patient clinic at Assiut University urology hospital.

Sample: Convenient sample for all elderly patients with BPH who attended the clinic. The sample's total number was determined using the previously described setting. The total number of elderly patients was around 500 every year. The sample is made up of (218) patients using the software EPI /Info, version 3, with a $95 \%$ confidence interval $(\mathrm{CI})$.

Inclusion criteria:

- Male patients aged 60 years and above diagnosed with BPH.

- Alert and able to communicate.

Exclusion criteria:

Patients who have a clear bladder pathology, such as a tumor or a stone.

Tools of the study:

Three tools were used in this study

Tool I: For data collection, an interview-structured questionnaire was created, which consists of three components.

First part: It includes demographic characteristics such as, age, marital status, residence, current occupations before retirement, level of education, and someone who supports the patient or lives with him.

Second part: it includes the patient's knowledge about BPH such as its definition, risk factors, signs and symptoms, and complication.

\section{Score system:}

Total scoring for knowledge was 17 degrees; correct responses scored one degree and the incorrect responses scored zero degree.

Total level of knowledge score was evaluated, scores transformed into percent

Percentage less than 50 is considered poor knowledge score, between 50-70 is considered fair, and percentage more than $70 \%$ is considered good knowledge score (Hassan A., 2021)

Tool II: Questionnaire of the health care seeking behaviors, expectations of treatment and unwanted side effects of medical treatments (Fan et al., 2017).

Tool III: International Prostate Symptom Score (IPSS) (American Urological Association, 1992). It includes seven questions about symptoms of $\mathrm{BPH}$ that ask the patients about how often they have (incomplete emptying -frequency -intermittency- 
urgency -weak stream -Straining -nocturia). And each answer is scored from (0) to 5 for a maximum score of (35) points. From ( $0-7)$ is mild symptom, (8$19)$ is moderate and (20-35) is severe symptoms.

\section{Validity of the sheet}

The sheet was reviewed by three experts in the urology and nephrology surgery and gerontological nursing staff at Assiut University, to assess and evaluate sheets items in order to score the validity of the sheet. Modifications were done according to the directions of the experts committee.

The tools Reliability:-

The Alpha Cronbach's test was used to determine internal consistency $=(0,812)$

Methods:

Administrative phase:

- A formal approval letter was directed from the dean of nursing faculty to the manager of urology hospital, Assiut University to carry out the study. The letter included a request for permission to conduct the study as well as an explanation of the study's objective and nature.

- Pilot study was carried out on (10\%) of old age patients to test clarity and feasibility of the questionnaire and estimated the time needed for filling the questionnaire. The necessary changes were made based on the findings of the pilot research. The patients who participated in the pilot study were excluded from the final analysis.

\section{Data Collection:}

The study started in first of May 2020 to the end of October 2020, the researcher collected data three days per week, 4 hours each day from 9 am to $1 \mathrm{pm}$. The interviewer selected patients who fulfilled the criteria. Each patient who volunteered to participate in the study was informed about the study's goal and nature. A verbal approval was obtained from participants and they were assured about confidentiality and privacy that the information and that data was used only for the purpose of research. Each patient was individually interviewed and the researcher recorded the answer in the questionnaire sheet. The approximate time spent during the filling of each sheet was around 30-45 minutes with an average of 3-4 patients / day.

A brochure containing pictures was developed in a simple Arabic language and was distributed to all the patients regarding definition, risk factors, management and prevention of $\mathrm{BPH}$.

\section{Ethical consideration:}

The ethical committee of Assiut University's nursing faculty approved the research proposal. During the implementation of the research, there was no risk for the study subjects during the carrying out of the research also the clinical research ethical principles were followed in the study. The right of refusing to participate for all elderly participants was assured and they can withdraw at any time from the study without any rationale. Informed consent will be obtained from all participants after explanation of the study purpose. Statistical analysis:

Data entry and data analysis were done using SPSS version 19. The Anderson-Darling Test for homogeneity variances prior to further statistical analysis was used. Categorical variables were described by number and percent $(\mathrm{N}, \%)$, where continuous variables described by mean and standard deviation (Mean, SD). Comparison between categorical variables was done by ChiSquare and continuous variables By ANOVA TEST and T-Test. We used Pearson Correlation to test the Association between scores and Multivariate linier regression to show the predictor variables of Scio demographic data. Statistical significance was defined as a two-tailed p 0.05. 


\section{Results:}

Table (1): Distribution of demographic characteristics of the studied elderly patients in outpatient clinic of urology hospital, Assiut university, 2020 ( $n=218)$.

\begin{tabular}{|c|c|c|}
\hline Items & No. (218) & $\%$ \\
\hline \multicolumn{3}{|l|}{ Age by year } \\
\hline - From $60-<70$ & 41 & 18.8 \\
\hline - $\geq 70$ & 177 & 81.2 \\
\hline Mean \pm SD(range) & \multicolumn{2}{|c|}{$71.14 \pm 4.94(60-85)$} \\
\hline \multicolumn{3}{|l|}{ Residence } \\
\hline - Urban & 81 & 37.2 \\
\hline - Rural & 137 & 62.8 \\
\hline \multicolumn{3}{|l|}{ Marital Status } \\
\hline - Married & 205 & 94.0 \\
\hline - Divorced & 5 & 2.3 \\
\hline - Widow & 8 & 3.7 \\
\hline \multicolumn{3}{|l|}{ Education Level } \\
\hline - Illiterate & 105 & 48.2 \\
\hline - Read and write & 60 & 27.5 \\
\hline - Basic Education & 21 & 9.6 \\
\hline - Secondary education & 11 & 5.0 \\
\hline - University education & 21 & 9.6 \\
\hline \multicolumn{3}{|c|}{ Someone who supports the patient or lives with him } \\
\hline - Alone & 9 & 4.1 \\
\hline - Wife & 111 & 50.9 \\
\hline - Son & 98 & 45.0 \\
\hline \multicolumn{3}{|l|}{ Occupation Before retirement } \\
\hline - Employee & 80 & 36.7 \\
\hline - Farmer & 63 & 28.9 \\
\hline - Free Business & 75 & 34.4 \\
\hline \multicolumn{3}{|l|}{ Current Occupation } \\
\hline - Not working & 104 & 47.7 \\
\hline - Farmer & 73 & 33.5 \\
\hline - Free Business & 41 & 18.8 \\
\hline
\end{tabular}

Table (2): Distribution of studied elderly according to elderly patient's knowledge about prostatic hyperplasia in outpatient clinic of urology hospital Assiut university, $2020(n=218)$.

\begin{tabular}{|l|c|c|}
\hline \multicolumn{1}{|c|}{ Item } & No. (218) & \% \\
\hline Meaning of BPH & & \\
\hline$\bullet$ Correct & 72 & 33.0 \\
\hline$\bullet$ Incorrect & 146 & 67.0 \\
\hline The high risk group to BPH \# & & \\
\hline$\bullet$ Elderly & 139 & 63.8 \\
\hline$\bullet$ Hereditary history & 50 & 22.9 \\
\hline$\bullet$ Hypertensive patients & 43 & 19.7 \\
\hline$\bullet$ Diabetes & 30 & 13.7 \\
\hline$\bullet$ Kidney disease & 20 & 9.2 \\
\hline Symptoms of the BPH \# & & \\
\hline$\bullet$ Incomplete empting of the bladder & 120 & 55.1 \\
\hline$\bullet$ Urinary incontinence & 20 & 9.2 \\
\hline$\bullet$ Straining during urination & 22 & 10.1 \\
\hline$\bullet$ Weak urinary stream & 49 & 22.5 \\
\hline$\bullet$ Urinary hesitancy & 43 & 19.7 \\
\hline
\end{tabular}




\begin{tabular}{|c|c|c|}
\hline \multicolumn{1}{|c|}{ Item } & No. (218) & \% \\
\hline$\bullet$ Urge to urinate & 30 & 13.8 \\
\hline$\bullet$ Pain during urination & 48 & 22.0 \\
\hline$\bullet$ Blood in Urine & 0 & 0.0 \\
\hline Complication of BPH & & \\
\hline$\bullet$ Urinary tract infection & 90 & 41.2 \\
\hline$\bullet$ Bladder stones & 30 & 31.0 \\
\hline$\bullet$ Chronic kidney disease & 48 & 22.0 \\
\hline
\end{tabular}

\# More than one answer was allowed.

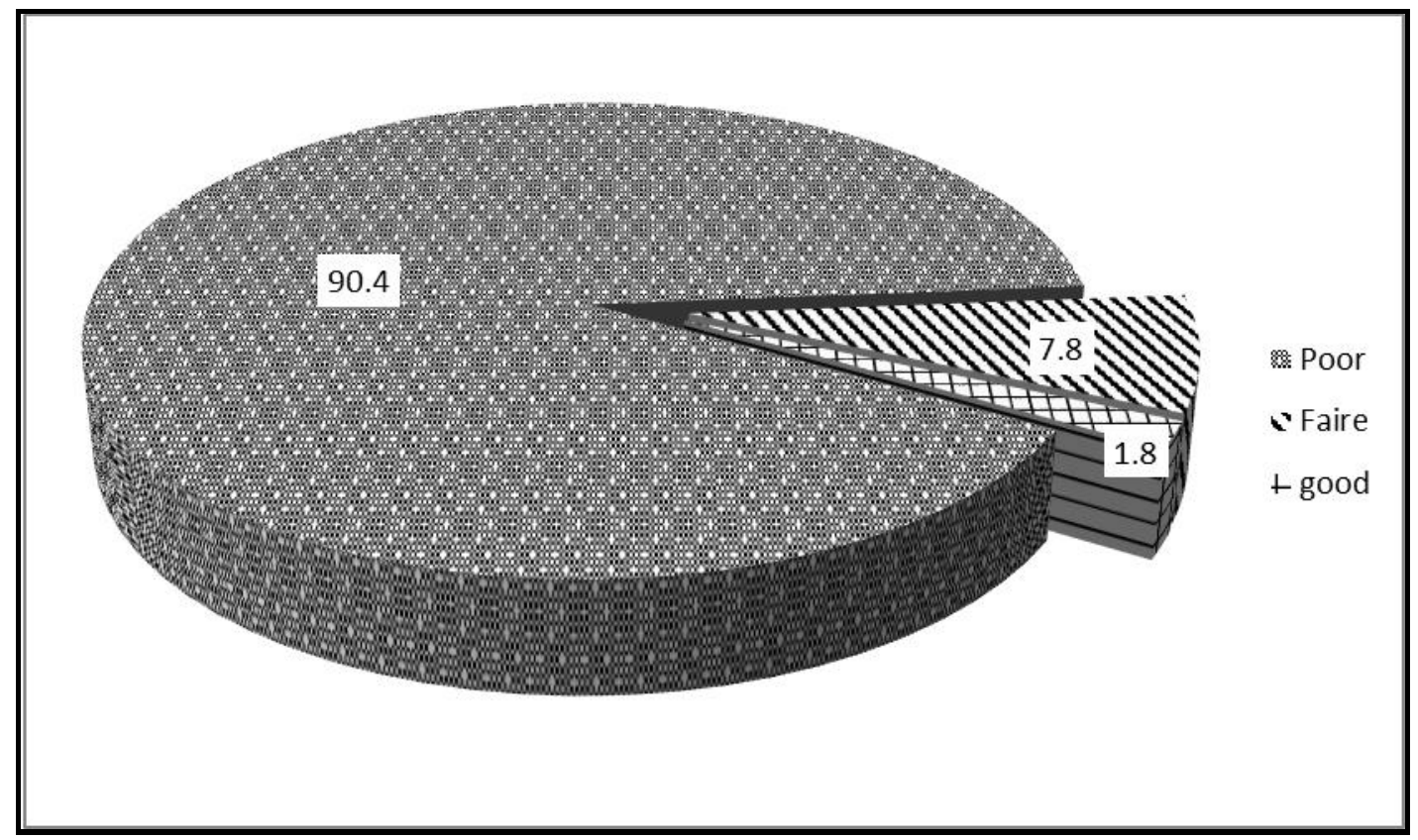

Figure (1): Distribution of studied patients related to knowledge about BPH in the outpatient clinic of urology hospital, 2020.

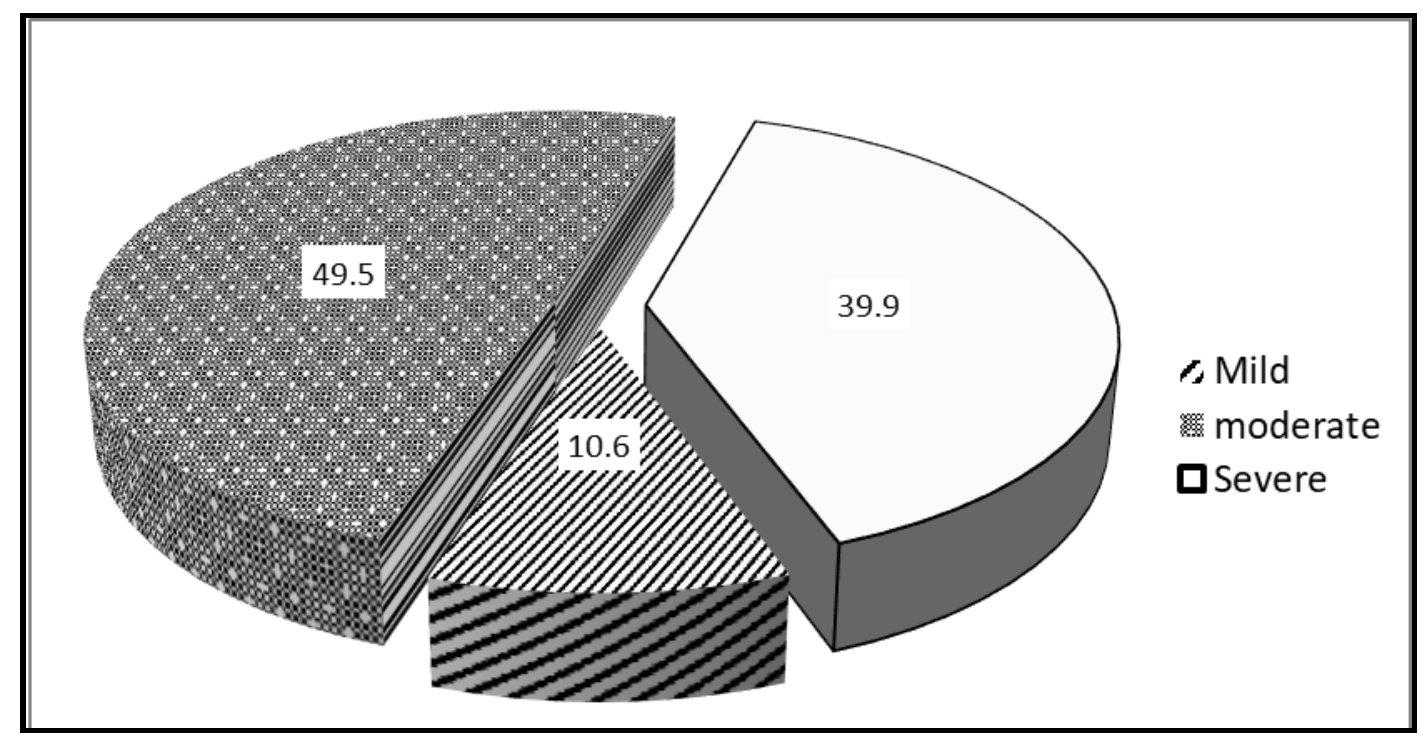

Figure (2): Distribution of the studied sample according to IPSS in outpatient clinic of urology hospital, Assiut University, 2020. 
Table (3): Distribution of studied patients regarding health care seeking behavior in outpatient clinic of urology hospital, 2020.

\begin{tabular}{|c|c|c|}
\hline \multicolumn{1}{|c|}{ Items } & No. (218) & \% \\
\hline Reason of patients' seeking medical advice & & 83.0 \\
\hline$\bullet$ Bothersome urinary symptoms & 181 & 11.0 \\
\hline$\bullet$ Attendance through physical check & 24 & 3.2 \\
\hline$\bullet$ Request by family or friends & 7 & 2.4 \\
\hline$\bullet$ Fear of prostate cancer & 6 & \\
\hline Expectations for BPH treatment & 65 & 29.8 \\
\hline$\bullet$ Reduction in the risk of requiring surgery & 97 & 44.5 \\
\hline$\bullet$ Reduction in the risk of urinary retention & 28 & 12.5 \\
\hline$\bullet$ Reduction in prostate size & 28 & 12.5 \\
\hline$\bullet$ Reduction in the risk of prostate cancer & & \\
\hline Unwanted side effects of medical treatment & 44 & 20.2 \\
\hline$\bullet$ Impairment of liver or kidney function & 63 & 28.8 \\
\hline$\bullet$ Impairment of sexual function & 85 & 39.0 \\
\hline$\bullet$ Dizziness & 26 & 11.9 \\
\hline
\end{tabular}

Table (4): Relation between patients' level of knowledge and demographic data in outpatient clinic of urology hospital 2020.

\begin{tabular}{|c|c|c|c|c|c|c|c|}
\hline \multirow{3}{*}{ Items } & \multicolumn{6}{|c|}{ Knowledge About BPH } & \multirow{3}{*}{ P. value } \\
\hline & \multicolumn{2}{|c|}{ Poor $(n=197)$} & \multicolumn{2}{|c|}{ Faire $(n=17)$} & \multicolumn{2}{|c|}{ Good $(n=4)$} & \\
\hline & No & $\%$ & No & $\%$ & No & $\%$ & \\
\hline \multicolumn{8}{|l|}{ Age group } \\
\hline - From $60-<70$ & 41 & 20.8 & 0 & 0.0 & 0 & 0.0 & \multirow{2}{*}{$0.068 \mathrm{NS}$} \\
\hline - $\geq 70$ & 156 & 79.2 & 17 & 100.0 & 4 & 100.0 & \\
\hline \multicolumn{8}{|l|}{ Residence } \\
\hline - Urban & 63 & 32.0 & 14 & 82.4 & 4 & 100.0 & \multirow{2}{*}{$<0.001 * *$} \\
\hline - Rural & 134 & 68.0 & 3 & 17.6 & 0 & 0.0 & \\
\hline \multicolumn{8}{|l|}{ Education Level } \\
\hline - Illiterate & 105 & 53.3 & 0 & 0.0 & 0 & 0.0 & \multirow{3}{*}{$<0.001 * *$} \\
\hline - Read and write & 60 & 30.5 & 0 & 0.0 & 0 & 0.0 & \\
\hline - Basic Education & 21 & 10.7 & 0 & 0.0 & 0 & 0.0 & \\
\hline - University education & 10 & 5.1 & 7 & 41.2 & 4 & $\mathbf{1 0 0 . 0}$ & \\
\hline \multicolumn{8}{|l|}{ Current Occupation } \\
\hline - Not working & 83 & 42.1 & 17 & 100.0 & 4 & 100.0 & \multirow{2}{*}{$<0.001 * *$} \\
\hline - Farmer & 73 & 37.1 & 0 & 0.0 & 0 & 0.0 & \\
\hline \multicolumn{8}{|c|}{ Someone who supports or lives with the patient } \\
\hline - Alone & 9 & 4.6 & 0 & 0.0 & 0 & 0.0 & \\
\hline - Wife & 90 & 45.7 & 17 & 100.0 & 4 & 100.0 & $<0.001 * *$ \\
\hline - Son & 98 & 49.7 & 0 & 0.0 & 0 & 0.0 & \\
\hline
\end{tabular}




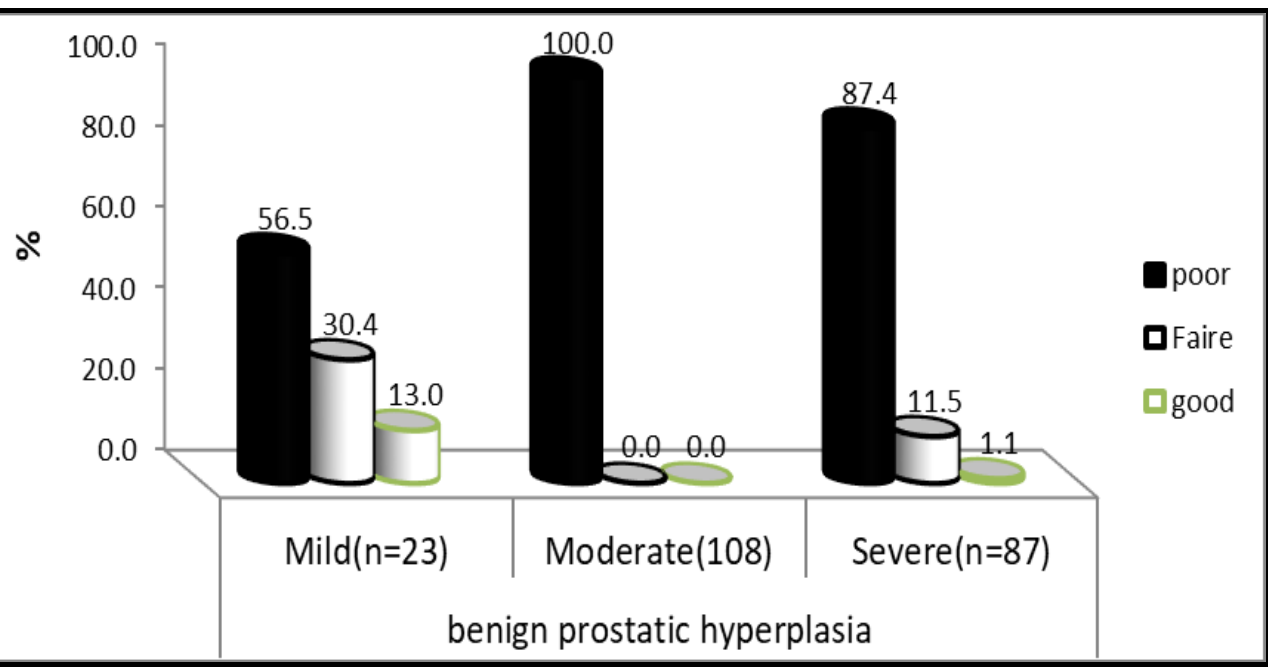

Figure (3): Relation between patients' knowledge and IPSS at outpatient clinics of urology hospitals Assiut University, 2020.

Table (5): Multivariate analysis of the demographic data affecting patients' knowledge about BPH.

\begin{tabular}{|l|c|c|c|}
\hline \multicolumn{2}{|c|}{ Item } & \multicolumn{2}{c|}{ Knowledge Score About BPH } \\
\cline { 2 - 4 } & Beta & t & Sig. \\
\hline Age & $\mathbf{0 . 2 3 3}$ & $\mathbf{5 . 0 9 6}$ & $\mathbf{0 . 0 0 0} * *$ \\
\hline$\bullet$ Residence & -0.013 & -0.301 & 0.763 \\
\hline$\bullet$ Marital Status & 0.053 & 1.307 & 0.193 \\
\hline Education level & $\mathbf{0 . 6 3 0}$ & $\mathbf{1 2 . 5 2 6}$ & $\mathbf{0 . 0 0 0} * *$ \\
\hline$\bullet$ Occupation before retirement & -0.019 & -0.407 & 0.684 \\
\hline Current occupation & $\mathbf{- 0 . 1 3 5}$ & $\mathbf{- 3 . 0 7 8}$ & $\mathbf{0 . 0 0 2} * *$ \\
\hline$\bullet$ Someone who supports or lives with the patient & 0.033 & 0.799 & 0.425 \\
\hline
\end{tabular}

**Statistically Significant Predictor at P. value <0.01

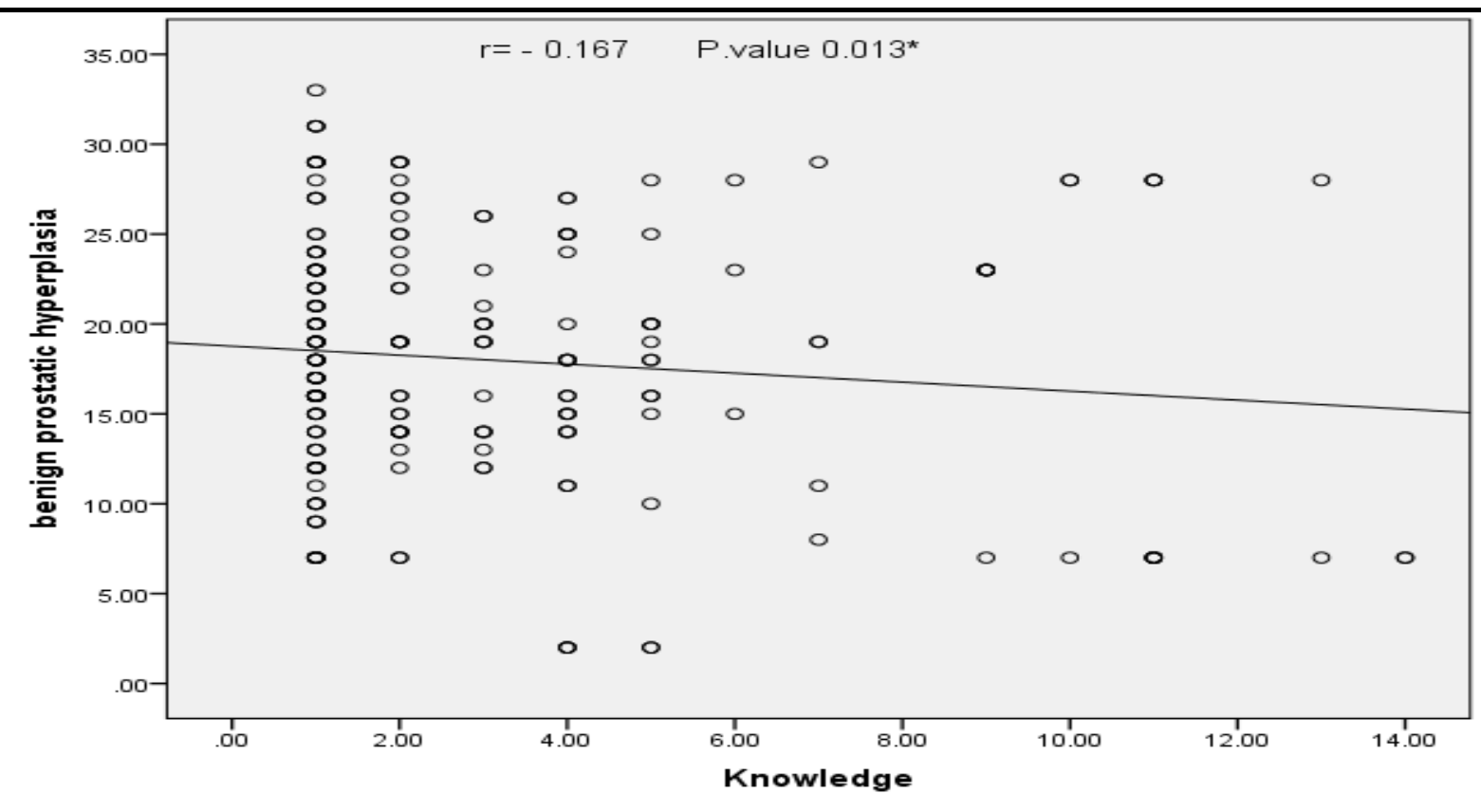

Figure (4): Correlation between total patients' knowledge score and total score of IPSS in outpatient clinic in urology hospital, 2020. 
Table (1): It shows that $81.2 \%$ of the patients aged 70 years and older, $62.8 \%$ live in rural areas and around half of them were illiterate.

Table (2): It shows that $67.0 \%$ of the studied patients do not know the meaning of BPH. However, about two thirds of them report that the elderly are the high risk group for BPH. Regarding to signs \& symptoms of $\mathrm{BPH}$, the current study reveal that more than half of the patient reported that sense of incomplete bladder emptying is the patient's main complain.

Figure (1): It shows that majority of them (90.4\%) have poor level of knowledge regarding $\mathrm{BPH}$.

Figure (2): It illustrates that $39.9 \%$ have sever symptom \& around half of them $49.5 \%$ have moderate symptoms.

Figure (3): It shows that majority of them (87.4\%) who have severe symptoms have poor knowledge regarding $\mathrm{BPH}$.

Figure (4): It shows that there is negative correlation between total knowledge and IPSS(r=-0.167)

Table (3): It shows that $83 \%$ of the patients are seeking medical advice when suffering from bothersome urinary symptom, and $39.0 \%$ of them report that dizziness is a side effect of medical treatment.

Table (4): It reveals that there is a significant difference between the level of knowledge of the studied sample with patient's education, residence, and current occupation with $\mathbf{P}=<0.001$.

Table (5): It illustrates the multivariate linear regression analysis of the demographic factors affecting patient's knowledge about BPH. The most important factors are educational level, age, and current occupation.

\section{Discussion:}

The most frequent disease of aging men is BPH, and it's often associated with painful LUTS that interfere with everyday activities and sleep patterns, lowering the quality of life. Histopathology of BPH is age dependent, with the majority of cases occurring after the age of 40 (Kok et al., 2017) According to metaanalyses of autopsy studies, around $50 \%$ of men in their sixth decade and $90 \%$ of men in their ninth decade have histologic BPH. (Lim, 2017).

The aim of this study was to assess the knowledge and health care seeking behaviors among old age patients with BPH attending outpatient clinic at urology hospital at Assiut University

The majority of the patients in this study were over the age of 70, according to the findings. This is supported by (Alma et al., 2018) whose conducted study in Saudi Arabian entitled as "BPH is a common disorder amongst elderly patients, it rarely causing signs and symptoms in young patients, especially in those younger than 40 years of age. This result might be due to improvement of diagnostic measures and curable treatment for those aged less than 40 years, they have more chances than older adults.

Another study done by (Chen et al., 2017) whose conducted in china entitled as "BPH patients were found to be above 60-year-old". About one-third of men experience moderate to severe symptoms by 60 years, and half do so by 80 years. This is related to aging and decrease in the amount of active testosterone in their blood, which leaves a higher proportion of estrogen and DHT that play a role in prostate development and growth.

Regarding marital status, it was noticed that the vast majority of the studied sample were married. This result disagreed with (Huey et al., 2017) whose conducted study in Taiwan who found that the majority of BPH patients were widows.

Regarding the level of education, the current study showed that around half of the patients were illiterate; this may be due to that, the level of education affect the cause of the disease. This is in agreement with the results of (Deep et al., 2017) whose conducted study in India and found that majority of the elderly patients suffering from $\mathrm{BPH}$ were not aware of their condition and that their health seeking behavior was generally poor. However, the present study disagreed with (Oranusi et al., 2017) whose conducted study in Nigeria reported that $74.1 \%$ of the respondents had higher awareness level of BPH with majority of the them being able to identify the condition. This related to that educated people seeking support as early as possible in reverse to illiterate ones.

This study presented that the majority of the studied patients live in rural areas. It can be interpreted that, the majority of studied patients live in rural areas and as result they have high health illiteracy about good nutrition, the importance of seeking medical advice when needed and a healthy lifestyle that may reduce the risk of BPH. In addition, lack of health facilities might be related to the inadequate health services in rural places with low medical team providers, big distance to medical centers, reduced specialist mass with increase dependence on generalists, and increase medical team turnover. (Huey et al., 2017).

These results agree with the study performed by (Ngugi et al., 2017) Who conducted a published study in Kenya reported that utilization of health services among resource limited in rural areas in Kenya which revealed that the distance was the main challenge associated affecting uptake of health care services.

On the other hand, these results differ from that recorded by (Pan et al., 2014) who conducted a published study in China who found that men in urban areas had a higher risk for BPH than those in rural. 
Regarding the patients' knowledge about the meaning of $\mathrm{BPH}$, the present study found that two thirds of them did not know the meaning of BPH while about one third of the elderly answered correctly. This may be due to the elderly not aware that they have changes with aging.

The present study showed that the vast majority of patients had a poor level of knowledge about BPH; this may be explained by the decline of learning skills and cognitive function in the elderly. This falls in the same line with (Zhang et al., 2019) whose conducted study in Mainland China who found that elderly people were less knowledgeable about BPH and less able to apply that knowledge. The present study presented that poor knowledge about $\mathrm{BPH}$ is increasing among patients with low educational level. This related to that educated patients may have access to knowledge about health.

According to the relationship between the knowledge level of elderly patent's and their demographics, there is no statistically significant difference between different age groups as regard level of knowledge in elderly patent's $\mathrm{P}=0.068 \mathrm{NS}$.

However, on multivariate analysis, age was found to be an independent significant factor $((\mathrm{p}=0.000)$. This is in agreement with (Lim, 2017) who found that there was a statistically significant relationship between age and knowledge level of elderly patients $\mathrm{P}=0.001$.

Regarding the multivariate linear regression analysis of the factors affecting knowledge level on the educational level of patients, it was an independent factor $(\mathrm{p}=\mathbf{0 . 0 0 0})$, this may be because of welleducated elderly patent's had good awareness and health information regarding their disease as BPH.

Regarding residence in the current study, it was notified that there was a statistically significant difference between the level of knowledge and residence of the study sample $P=0.001$, this may be related to those elderly patients who lived in urban areas can receive many different health services with easy transportation in reverse to elderly participants who lived in rural areas.

In addition, the present study showed that there was a statistically significant difference between the educational status of elderly patients and their knowledge level $\mathrm{P}=<0.001$, this may be because illiterate elderly patients had no awareness and health information regarding their disease as BPH.

The current study displayed that more than one-third of the patients had severe symptoms \& about half of them had a moderate symptom. While in (Nickel., 2017) who conducted study in Australia who found moderate symptom were more prevalent among $\mathrm{BPH}$ patients, while about (24\%) of them had severe symptoms.
The present study showed that $83 \%$ are seeking medical advice when suffering from bothersome urinary symptoms. This is an agreement with (Steven et al., 2014) who found that the majority of the patients seeking medical advice because of bothersome urinary symptoms. From the investigator point of view, these results explained the bothersome was the most common symptoms of $\mathrm{BPH}$ to diagnose the disease.

The present study revealed that less than half of the patients expect a reduction in risk of urinary retention from treatment. This is in agreement with (Fan et al., 2017) who conducted a published study in Taiwan who reported that nearly half of the patients $48.6 \%$ were very concerned about the risks of long-term complications, namely, acute urinary retention; patients reported that they would rather have a drug that prevents retention than one that delivers faster symptom alleviation.

The present study presented that more than one-third of the patient reported dizziness as an unwanted side effect of medical treatment. This is in disagreement with (Nix \& Carson., 2017) who conducted a published study in Canada who reported kidney and liver function impairments are the most commonly reported adverse effects of medical treatment (73.3\%), followed by sexual function impairment $(10.9 \%)$, and dizziness $(3.0 \%)$ it may be Appear another factors can aggravate dizziness as antihypertensive drugs.

The result of the current study showed that there was a significant -ve correlation between patient's knowledge score and IPSS $(r=-0.167)$.

\section{Conclusion: \\ Conclusion Based on the current study results, it could be concluded that:}

The current study displayed that the majority of the studied patients had poor knowledge score and came from rural areas, had low level of education and seek medical advice when suffering from bothersome symptom and fear of urinary retention.

\section{Recommendations:}

Based on the present study results, the following is recommended

- Providing booklet or handout to increase the knowledge of elderly patients with BPH about disease: causes, risk factors, treatment, and complications, importance of regular exercise, fluids restrictions and complications prevention.

- Health education about routine follow up and early detection of BPH disease especially in high risk groups. 
- Screening for all people above the age of 60 years for early detection of BPH at outpatient clinics.

- Future research of screening effect on early detection of BPH disease especially in high risk groups.

\section{References:}

- American Urological Association, (1992): Urological science and research foundation. At http://www.urospec.com/uro/forms/ipss.pdf.

- Ali T, ElHariri, M, \& Riad M, (2018): Diffusionweighted MRI in prostatic lesions: Diagnostic performance of normalized ADC using normal peripheral prostatic zone as a reference. Egypt J Radiol Nucl Med 49(1):239-244. https://doi.org/10.1016/j.ejrnm.09.007 8.

- Alma, M, Sawma, A, Alruwaili, F, Alsaqabi, A, Alonazi, M, Alruwaili, W, \& Alanazi, N., (2018): Prevalence of Benign Prostatic Hyperplasia (BPH) in Saudi Patients above 40 Years Old The Egyptian Journal of Hospital Medicine (January) Vol. 70 (7), Page 1137-1139

- Alghazaly G Mohamed., Abd El Raouf Y Mahmoud., \& Zaglol K., (2016): Impact of Benign Prostatic Hyperplasia (BPH) on Health Related Quality of Life in, Egypt. Global Advanced Research Journal of Medicine and Medical Sciences Vol. 5(2), Pp: 53- 66.

- Central agency for mobilization and statistics, (2019): General health census, Egypt.

- Chen X, Zhang W, Chen X, Ping Y \& Ruan L. (2017): Effect of evidence based nursing on the prognosis and curative effect of patients with hypertensive cerebral hemorrhage. Chinese Journal of Primary Medicine and Pharmacy; 24: 3041-3045.

- Deep, A., Ingle G.K., \& Kishore J. (2015): Benign Prostatic Hyperplasia: Health Seeking Behaviour of patients at a tertiary care hospital. AMJ, 1, 3, 213-216. Retrieved 1 March.

- Ebere Zepherinus Obasi. (2016): A Review of the Barriers and Socio-Cultural Factors Influencing the Access to Maternal Health Care Services in Nigeria. Lagos: Helsinki Metropolia University

- Fan,Y,Lin, A, Huang, Y, \& Chen, K, (2017): Health care seeking behaviorl in prostatic hyperplasia patients.Taiwan urology association ,Uorological science ,Jornal 28.169 -173

- Huey, S., Chan, E., \& Lai., y, (2017): The global burden of lower urinary tract symptoms suggestive of benign prostatic hyperplasia: A systematic review and metaanalysis Taiwan Journal of Urology $185,1793-1803$

- Hassan., (2021): Knowledge \& Health Attitude of students toward fast food in Assiut University thesis submitted for partial fulfillment of the requirements for master Degree in Community health Nursing.
- Kuang M, Vu A, \& Athreya S, (2017): "A systematic review of prostatic artery embolization in the treatment of symptomatic benign prostatic hyperplasia ". Cardiovasc Intervent Radiol. 40(5): 655-663.

- Kok ET, Schouten BW, Bohnen AM, Groeneveld FP, Thomas S, \& Bosch JL. (2017): Ris Singapore, Singapore and 3 School of Nursing and Midwifery, Faculty of Health and Medicine k factors for lower urinary tract symptoms suggestive of benign prostatic hyperplasia in a community based population of healthy aging men: the Krimpen Study. J Urol;181:7106

- Lim, K (2017): Epidemiology of clinical benign prostatic hyperplasia ,Singapore urology association, urological scince journal 4,148-151

- Lee, S., Hyub Lee, S., So, A., Park, J., Lee, S., Oh, I., \& Oh, C. (2017): Risk of Suicide Among Patients with Benign Prostatic Hyperplasia in South Korea: A Nationwide Retrospective Cohort Study. Ah-Hyun and Park, Jong-Ik

- Lewis, S., Bucher, L., Heitkemper, M., \& Dirksen, S. (2014): Clinical Companion to Medical-Surgical Nursing-E-Book. Elsevier Health Sciences.

- Mason, A, \& Ronald L (2017): Intergenerational transfers and the older population. In Future Directions for the Demography of Aging: Proceedings of a Workshop, M.D. Hayward and M.K. Majmundar, eds. National Academies of Sciences, Engineering, and Medicine. The National Academies Press. https://doi.org/10.17226/25064.

- Michalak, J; Tzou, D; \& Funk, J. (2015): "HoLEP: the gold standard for the surgical management of BPH in the 21(st) Century.". American journal of clinical and experimental urology 3 (1): 36-42.

- Ngugi Ak, Agoi F, Mahoney MR, Lakhani A, Mang'onge'o D, Nderitu E, Armstrong $R$, \& Macfarlane S (2017): Utilization of health services in a resource- limited rural area in Kenya: Prevalence and associated household-level factors. Pubmed central

- Nix, j, \& Carson, C. ( 2017): medical management of benign prostatic hyperatrophy .Can,J, Urol:17 (supp 1):53-7

- Nickel JC, Freedland SJ, Castro-Santamaria R, \& Moreira DM (2017): Chronic prostate inflammation predicts symptom progression in patients with chronic prostatitis /chronic pelvic pain. J Urol. Jul;198 (1):122-8.

- Oranusi C, Nwofor A, \& Mbonu O., (2017): Correlation between international prostate symptom score and uroflowmetry in patients with benign prostatic hyperplasia. Niger J Clin Pract;20:454-8. 
- Rosen R., Altwein J., Boyle P., Kirby R.S., Lukacs B., \& Meuleman E., (2017): Lower urinary tract symptoms and male sexual dysfunction: the multinational survey of the aging male (MSAM-7). Eur Urol; 44: pp. 637-649.

- Steven J. Jacobsen, M, PhD; Harry A. Guess, M, PhD; Laurel Panser, MA, MS; Cynthia J. Girman, MS; Christopher G. Chute, MD, DrPH; Joseph E. Oesterling, MD; Michael M. \& Lieber, (2014): MDA Population-Based Study of Health Carelp=m-ISeeking Behavior for Treatment of Urinary Symptoms The Olmsted County Study of Urinary Symptoms and Health Status Among Men ,Epidemiol Rev. 14:131-153

- Saigal, C. \& Joyce, G. (2015): Economic costs of benign prostatic hyperplasia in the private sector. J Urol 173, 1309-13.

- Tourani, S, Behzadifar, M, Martini, M, Aryankhesal, A Mirghaed, M.T, Salemi, M,Behzadifar, M, Bragazzi, N.L. (2018): Healthrelated quality of life among healthy elderly Iranians: A systematic review and meta-analysis of the literature. Health Qual. Life Outcomes, 16: 181136

- World Health Organization, (2019): Available at: http://www.who.int/healthinfo/survey/whoqolqualit yoflife/en/index 4.html.

- Pan, J., Jiang, C., Luo, R. \& Zhou, X. (2014): Association of metabolic syndrome and benign prostatic hyperplasia in Chinese patients of different age decades. Urol Int 93, 10-6 (2014).

- Zhang, J., Cai, Z., Xiong, J., \& Li, H. (2019):

Defining the Efficacy and Safety of Phosphodiesterase Type 5 Inhibitors with Tamsulosin for the Treatment of Lower Urinary Tract Symptoms econdary to Benign Prostatic Hyperplasia with or without Erectile Dysfunction: A Network Meta-Analysis. BioMed Research International, 